\title{
Systematic early versus late mobilization or standard early mobilization in mechanically ventilated adult ICU patients: systematic review and meta-analysis
}

Dominik Menges $^{1^{*}(\mathbb{D}}$, Bianca Seiler ${ }^{2}$, Yuki Tomonaga $^{1}$, Matthias Schwenkglenks ${ }^{1,3}$, Milo A. Puhan ${ }^{1}$ and Henock G. Yebyo'

\begin{abstract}
Background: This systematic review and meta-analysis aimed to determine the effectiveness of systematic early mobilization in improving muscle strength and physical function in mechanically ventilated intensive care unit (ICU) patients.

Methods: We conducted a two-stage systematic literature search in MEDLINE, EMBASE and the Cochrane Library until January 2019 for randomized controlled trials (RCTs) examining the effects of early mobilization initiated within 7 days after ICU admission compared with late mobilization, standard early mobilization or no mobilization. Priority outcomes were Medical Research Council Sum Score (MRC-SS), incidence of ICU-acquired weakness (ICUAW), 6-min walk test (6MWT), proportion of patients reaching independence, time needed until walking, SF-36 Physical Function Domain Score (PFS) and SF-36 Physical Health Component Score (PCS). Meta-analysis was conducted where sufficient comparable evidence was available. We evaluated the certainty of evidence according to the GRADE approach.

Results: We identified 12 eligible RCTs contributing data from 1304 participants. Two RCTs were categorized as comparing systematic early with late mobilization, nine with standard early mobilization and one with no mobilization. We found evidence for a benefit of systematic early mobilization compared to late mobilization for SF-36 PFS (MD 12.3; 95\% Cl 3.9-20.8) and PCS (MD 3.4; 95\% Cl 0.01-6.8), as well as on the proportion of patients reaching independence and the time needed to walking, but not for incidence of ICUAW (RR 0.62; 95\% CI 0.38-1.03) or MRC-SS. For systematic early compared to standard early mobilization, we found no statistically significant benefit on MRC-SS (MD 5.8; 95\% $\mathrm{Cl}-1.4$ to 13.0), incidence of ICUAW (RR 0.90; 95\% Cl 0.63-1.27), SF-36 PFS (MD 8.1; 95\% Cl - 15.3 to 31.4) or PCS (MD $-2.4 ; 95 \% \mathrm{Cl}-6.1$ to 1.3$)$ or other priority outcomes except for change in 6MWT from baseline. Generally, effects appeared stronger for systematic early compared to late mobilization than to standard early mobilization. We judged the certainty of evidence for all outcomes as very low to low.
\end{abstract}

Conclusion: The evidence regarding a benefit of systematic early mobilization remained inconclusive. However, our findings indicate that the larger the difference in the timing between the intervention and the comparator, the more likely an RCT is to find a benefit for early mobilization.

\footnotetext{
*Correspondence: dominik.menges@uzh.ch

${ }^{1}$ Department of Epidemiology, Epidemiology, Biostatistics

and Prevention Institute (EBPI), University of Zurich, Hirschengraben 84,

8001 Zurich, Switzerland

Full list of author information is available at the end of the article
}

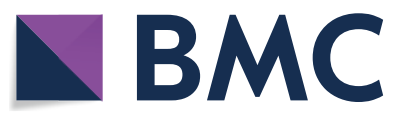

(c) The Author(s) 2021. Open Access This article is licensed under a Creative Commons Attribution 4.0 International License, which permits use, sharing, adaptation, distribution and reproduction in any medium or format, as long as you give appropriate credit to the original author(s) and the source, provide a link to the Creative Commons licence, and indicate if changes were made. The images or other third party material in this article are included in the article's Creative Commons licence, unless indicated otherwise in a credit line to the material. If material is not included in the article's Creative Commons licence and your intended use is not permitted by statutory regulation or exceeds the permitted use, you will need to obtain permission directly from the copyright holder. To view a copy of this licence, visit http://creativecommons.org/licenses/by/4.0/. The Creative Commons Public Domain Dedication waiver (http://creativeco mmons.org/publicdomain/zero/1.0/) applies to the data made available in this article, unless otherwise stated in a credit line to the data. 
Study Registration: PROSPERO (CRD42019122555).

Keywords: Early mobilization, Rehabilitation, Intensive care, Critical care, ICU, Physical therapy, Mechanical ventilation, Systematic review, Meta-analysis

\section{Background}

Patients in intensive care units (ICUs) frequently suffer from ICU-acquired weakness (ICUAW) and lasting physical and neurocognitive impairment, resulting in difficulties in achieving full functionality in their social and professional lives [1-3]. As a consequence, ICU stays are associated with a reduced quality of life as well as increased utilization of medical care, costs and mortality $[2,3]$.

The systematic early mobilization of ICU patients is commonly advocated as an intervention to improve patient outcomes $[1,4]$ and is part of various clinical practice guidelines [5-9]. There is evidence from several studies that early mobilization may improve physical function, decrease the risk of acquiring ICUAW or delirium and shorten the time to weaning from mechanical ventilation [10-13]. However, some systematic reviews found no or inconclusive evidence for a benefit $[14,15]$. It is not fully clear how the inconsistency in effects between studies arises. While heterogeneity in study populations and modality or intensity of study interventions may play a role [15], the timing of early mobilization has been discussed as an important factor for the effectiveness of the intervention, with earlier interventions showing greater benefit [4]. However, the definition of standard care is not consistent between trials and may have changed over time as early mobilization was increasingly adopted in clinical practice. Thus, standard care may involve mobilization approaches that are also provided early, but less systematically $[4,15]$. This may complicate the evaluation of the effects of early mobilization.

In this systematic review and meta-analysis, we aimed to determine the effectiveness of systematic early mobilization in mechanically ventilated adult ICU patients, while explicitly considering the timing of the delivery of the comparator intervention.

\section{Methods}

We conducted this systematic review in line with the Preferred Reporting Items for Systematic Reviews and Meta-Analyses (PRISMA) and Cochrane Collaboration recommendations $[16,17]$. A protocol was registered a priori on PROSPERO (CRD42019122555).

\section{Eligibility criteria \\ Population}

We included studies conducted in adult ICU patients (aged $\geq 18$ years) requiring invasive or non-invasive mechanical ventilation at enrollment or during the ICU stay. We excluded studies that enrolled relevant proportions ( $\geq 10 \%$ ) of patients with burn injuries, neurological conditions or transplant patients, as well as studies conducted in postoperative patients requiring ventilation for less than $24 \mathrm{~h}$ on average, as we considered these patients to have different needs or be at higher risk for adverse events than other ICU patients.

\section{Intervention}

The experimental intervention of interest was systematic early mobilization, which we defined as any physical or occupational therapy targeting muscle activation, initiated within 7 days after ICU admission and performed according to a clearly defined protocol or specific clinical criteria in all eligible patients. Neurocognitive interventions, speech therapy and ICU diary keeping were considered eligible as part of an early rehabilitation approach including systematic mobilization. Studies examining interventions primarily targeted at preventing pressure ulcers or joint stiffness, or respiratory therapy alone were not included.

\section{Comparators}

Based on a priori-defined criteria, eligible comparators were categorized as: (i) late mobilization (i.e., mobilization initiated 7 days or more after ICU admission), (ii) standard early mobilization (i.e., mobilization initiated within 7 days but less systematically, as outlined above) or (iii) no mobilization (i.e., sham intervention or no rehabilitative intervention).

\section{Outcomes}

As part of a comprehensive assessment, we prespecified multiple primary outcomes related to muscle strength and functional mobility and secondary outcomes related to quality of life, mortality, length of stay and safety (see Additional file 1). Follow-up time points considered included ICU discharge, hospital discharge, as well as 3, 6 and 12 months after hospital discharge. Out of all outcomes, the most clinically important and patient-relevant outcomes were prioritized by four ICU experts involved 
as stakeholders in this project without prior knowledge of the data. Here, we primarily report on these priority outcomes, which include the Medical Research Council Sum Score (MRC-SS) at ICU discharge, proportion of patients developing ICUAW during hospitalization, 6-min walk test (6MWT) performance, time needed until walking for the first time, proportion of patients returning to independence from assistance, SF-36 Physical Function Domain Score (PFS) and SF-36 Physical Health Component Summary Score (PCS) at 6 months after discharge.

\section{Study types}

Only randomized controlled trials (RCTs) published in English, German, French or Italian language were included. We did not consider observational evidence as we assumed a high probability of confounding by indication and differences in the provision of early mobilization between patients in a non-standardized, non-randomized setting.

\section{Information sources and search strategy}

To identify relevant studies, we followed a two-stage systematic search process based on previously published high-quality systematic reviews. In the first stage, we systematically searched the MEDLINE and Cochrane Library databases for relevant systematic reviews published between 2015 and 2019. We assessed the identified systematic reviews in full text for eligibility and selected high-quality systematic reviews based on the Assessing the Methodology of Systematic Reviews (AMSTAR 2) assessment checklist [18]. The selected high-quality systematic reviews were then used as a basis to identify potentially eligible RCTs. All records identified in these reviews were included in the full-text assessment in the second stage of our systematic review.

In the second stage, we performed a systematic followup search in the MEDLINE, EMBASE, CINAHL and CENTRAL databases to identify more recently published studies. We adopted the search strategies of the high-quality reviews, additionally applying the Cochrane sensitivity and precision-maximizing RCT filter [19]. Each search was conducted for a timeframe starting two months prior to the last search in the respective review up to January 17, 2019, to account for a potential lag in the indexing of publications (see Additional file 1 for detailed search strategies). Additional references were identified through bibliographies of included studies and registry records. We screened the title and abstract of all records retrieved through the update searches and pooled potentially eligible records with the records retrieved from the high-quality systematic reviews. After deduplication, we assessed the pooled references in full text to select eligible studies. All study selection processes were carried out independently and in duplicate by three reviewers. Disagreements were resolved by consensus with an experienced senior reviewer.

\section{Data extraction}

We extracted information regarding the study design, study population characteristics, intervention and comparator details (i.e., modality, timing, frequency, duration), measured outcomes and follow-up. Where reporting of intervention, comparator or results was insufficient to allow judgments about the categorization of studies, we consulted study protocols and contacted authors for additional information. Data extraction was performed in duplicate by three reviewers.

\section{Risk of bias assessment}

We assessed the risk of bias of included RCTs using the Cochrane risk of bias tool $[17,20]$ and evaluated studylevel bias as recommended by the Agency for Healthcare Research and Quality (AHRQ) [21]. As blinding of personnel is commonly not possible in the context of rehabilitative interventions, this domain was not considered for the study-level assessment.

\section{Data synthesis}

We primarily used a narrative synthesis due to the high heterogeneity between RCTs, measured outcomes and follow-up time points. As we considered the comparator interventions to be a major source of heterogeneity, we report results stratified by comparator category (i.e., late mobilization, standard early mobilization or no mobilization). Studies were categorized according to the timing and the nature of the comparator intervention. Studies in which the comparator did not meet the definition of early mobilization were assigned to the late mobilization category. Studies in which the comparator was also administered early, but in a less protocol-driven and consistent manner, according to less strict criteria or not in all eligible patients, were assigned to the standard early mobilization category. Studies that could not be categorized with respect to the timing of the comparator were also assigned to the standard early mobilization category, in order to enable separate evaluation of studies in which a clear timing difference between groups was present (i.e., comparing early with late mobilization). Studies with a sham procedure or no rehabilitative intervention as comparator were assigned to the no mobilization category.

We conducted pairwise fixed- and random-effects meta-analyses for outcomes that were reported by at least three studies. Studies reporting median and interquartile range (IQR) only were not included in the metaanalyses. We report risk ratios (RRs) for dichotomous outcomes and mean differences (MD) for continuous 
outcomes. Study heterogeneity was assessed visually using forest plots and statistically using the $I^{2}$-statistic. We further conducted sensitivity analyses to explore heterogeneity. We planned to conduct heterogeneity assessment based on predefined factors (continuation of the intervention post ICU discharge, intervention type, study population characteristics, study-level risk of bias) and to assess small study effects using funnel plots and Egger's test, where appropriate. However, the number of studies for each reported outcome was too low to allow a meaningful assessment. Preplanned subgroup analyses based on age and length of ICU stay were not possible because no separate data were reported for these populations. We used R (version 3.5.2) for all statistical analyses.

\section{Confidence in evidence}

We assessed the confidence in the evidence using the Grading of Recommendations Assessment, Development, and Evaluation (GRADE) approach for the priority outcomes [22].

\section{Results \\ Study selection}

In the first stage of the literature search, we found three high-quality systematic reviews published between 2015 and 2019 [12, 14, 15], through which we identified 108 references. In the second stage, the systematic update search yielded further 2,299 records, and six references were identified through bibliographies from relevant publications. Twelve studies were finally included in the qualitative and quantitative analysis [23-34]. Figure 1 shows the study selection process and the main reasons for exclusion at the different stages.

\section{Study characteristics}

The included studies provided data from 679 people randomized to systematic early mobilization and 625 people receiving one of the comparators. We categorized two studies as comparing systematic early against late mobilization [23, 32] and the majority of studies (9 out of 12) as comparing systematic early against standard early mobilization [24-29, 31, 33, 34]. Six studies did not report information on the time from ICU admission to first mobilization in the intervention group [24, 25, 2729,33 ]. Information about the timing difference between intervention and comparator group was unavailable for six studies [25-29, 33], which were thus included in the standard early mobilization category. One study was categorized as comparing systematic early mobilization against no mobilization, but contributed data to secondary outcomes reported in Additional file 3 only [30].

An overview of the included studies, study participant characteristics and interventions is provided in Tables 1 and 2. There was considerable heterogeneity in the baseline characteristics of participants in terms of gender, age and disease severity, both between studies and between intervention and comparator groups within studies. While most studies included a diverse mix of diagnoses, three studies focused on specific populations such as cardiothoracic surgery $[29,30]$ or sepsis patients [28]. While interventions primarily involved physical therapy, one study additionally investigated combined physical and cognitive therapy in one of the intervention groups [26]. Two studies involved occupational therapy [23, 26] and two included neuromuscular electro-stimulation [28, 30]. None of the studies involved speech therapy or ICU diary keeping in addition to early mobilization.

\section{Risk of bias and certainty of evidence}

We considered nine out of twelve RCTs to be at high risk of bias in one or more criteria and therefore rated them as of 'poor overall quality' [24-32]. Two studies were judged to be of 'good overall quality' [23, 34] and one study of 'fair overall quality' [33]. The most frequent issues apart from the blinding of participants and personnel were incomplete outcome data and concerns related to selective reporting. Figure 2 shows an overview of the risk of bias assessment (see Additional file 2 for details). While the number of RCTs reporting results for each priority outcome was low, we found no indication for a small study effect that may have influenced our results. The GRADE assessment of the certainty of evidence is presented in Table 3.

\section{MRC Sum Score}

Five studies reported on MRC-SS [23, 24, 28, 31, 34] at ICU discharge. Four studies found no statistically significant difference between systematic early mobilization and late mobilization [23] or standard early mobilization [28, 31, 34]. Dantas et al. reported a statistically significantly higher MRC-SS in favor of systematic early mobilization compared with standard early mobilization [24]. However, the mean MRC-SS of participants in the systematic early mobilization group was already higher at baseline compared to the comparator group. Metaanalysis including data from four studies (203 patients) $[24,28,31,34]$ showed no statistically significant difference in MRC-SS at ICU discharge between systematic early mobilization and standard early mobilization (MD 5.8 points, $95 \%$ confidence interval $(\mathrm{CI})-1.4$ to 13.0 ; $p=0.12 ; I^{2}=81.7 \%$; very low certainty; Fig. 3$)$. In a sensitivity analysis, we excluded the study by Dantas et al. due to the baseline imbalance in MRC-SS, which may have affected their results. We found no evidence for a between-group difference in this analysis (MD 2.2; 95\% CI -2.5 to $6.9 ; p=0.36 ; I^{2}=41.2 \%$; low certainty). 


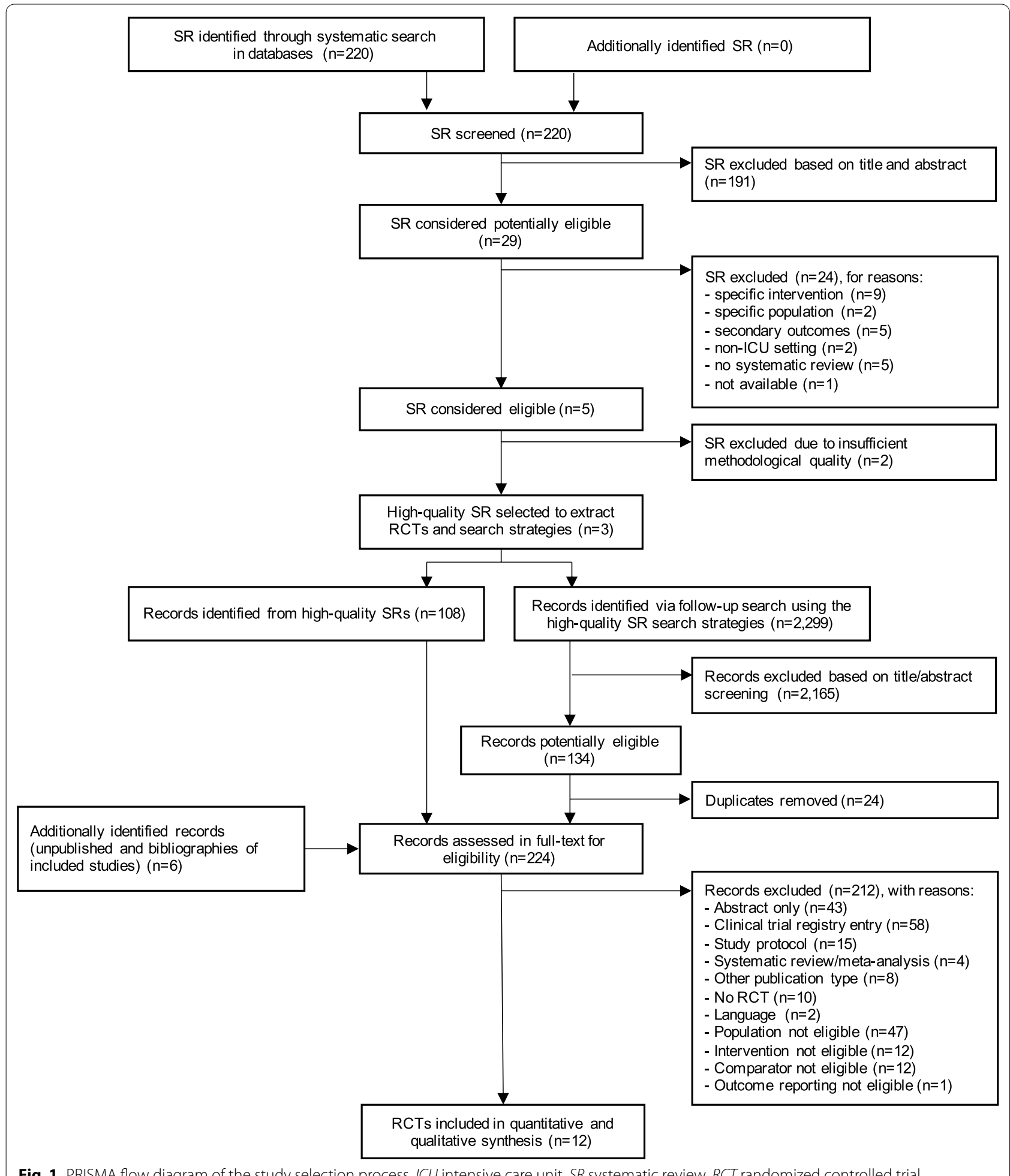

Fig. 1 PRISMA flow diagram of the study selection process. ICU intensive care unit, SR systematic review, $R C T$ randomized controlled trial

\section{Proportion of patients developing ICUAW during hospitalization}

While four studies published results on the proportion of patients developing ICUAW during hospitalization [23,
$25,31,33]$, none of these found a statistically significantly lower rate of ICUAW in the systematic early mobilization group compared to late mobilization [23] or standard early mobilization groups [25, 31, 33]. A meta-analysis of 


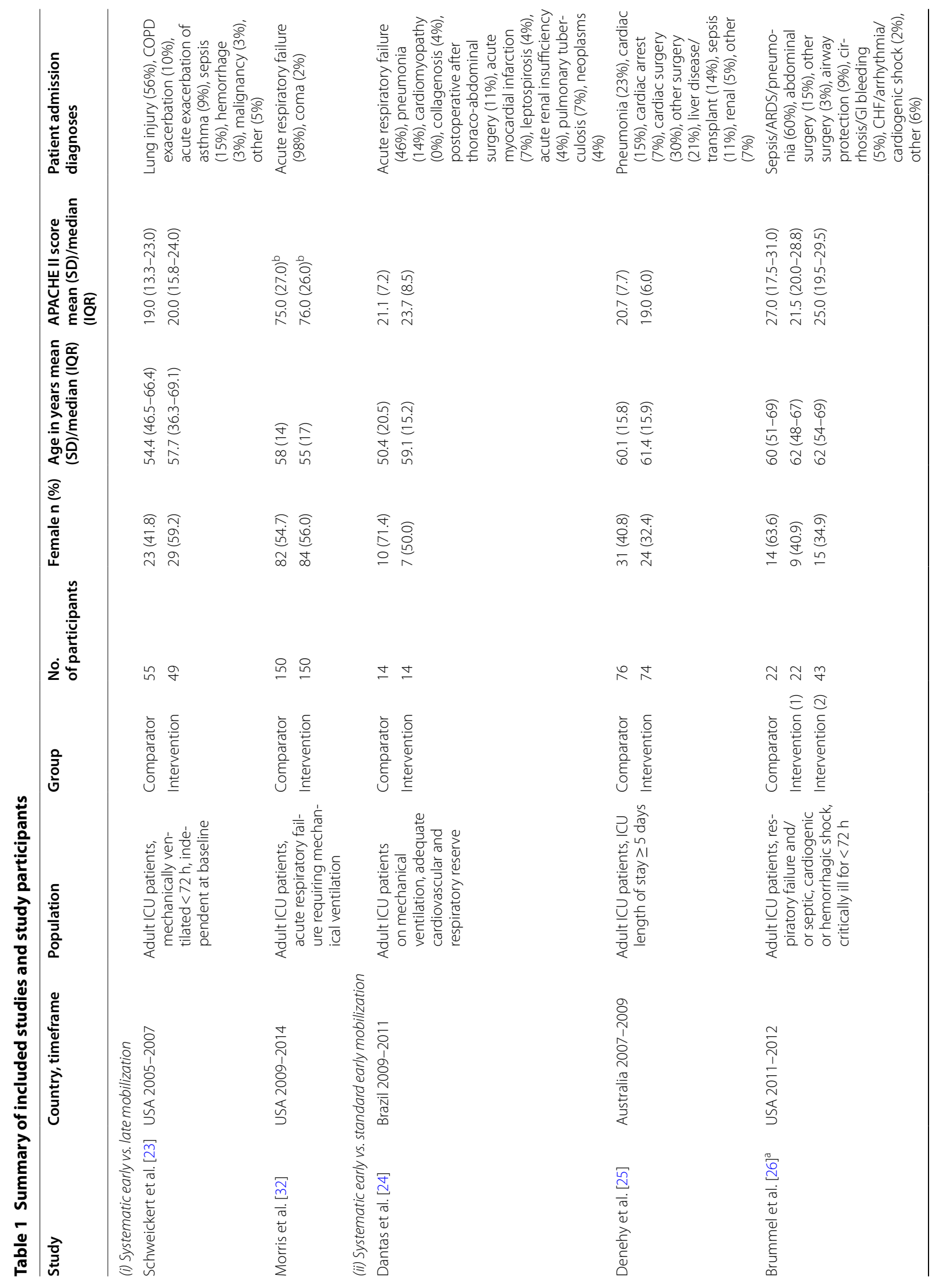




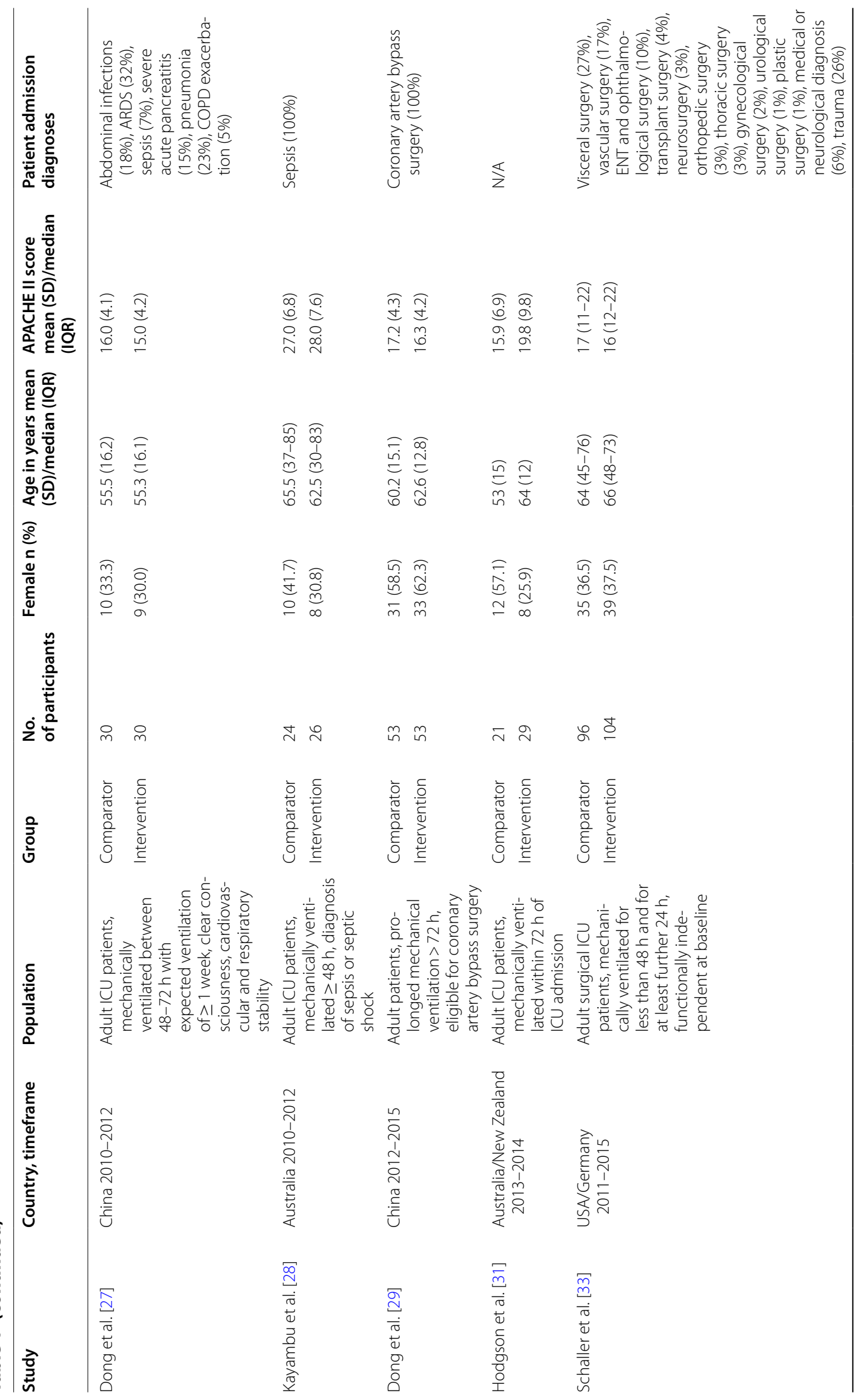




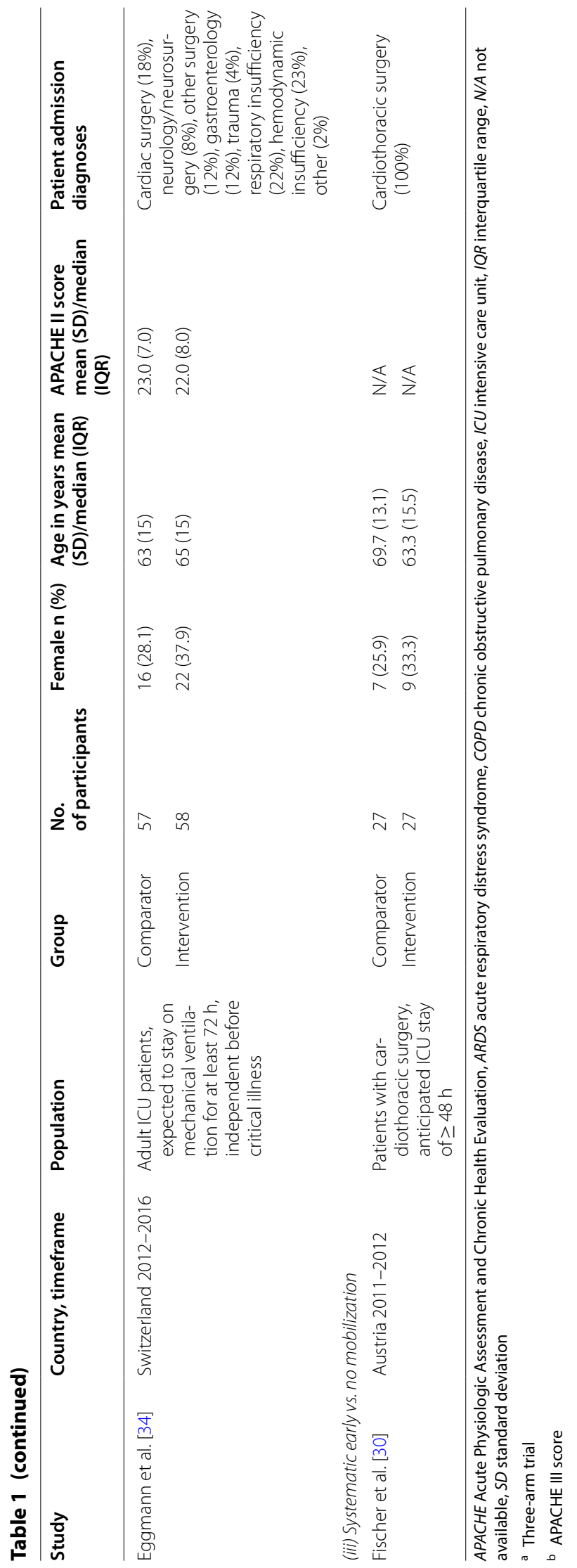




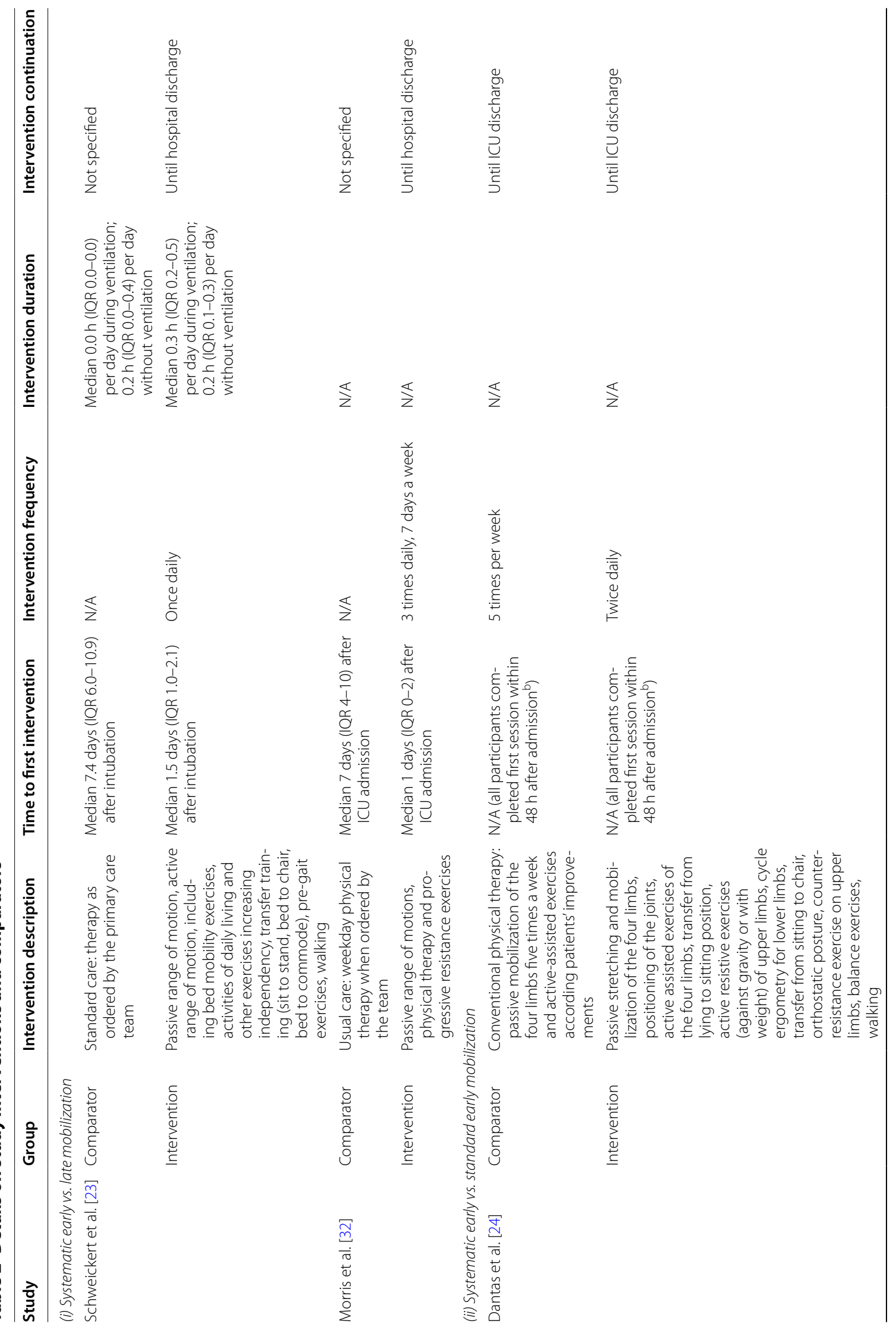




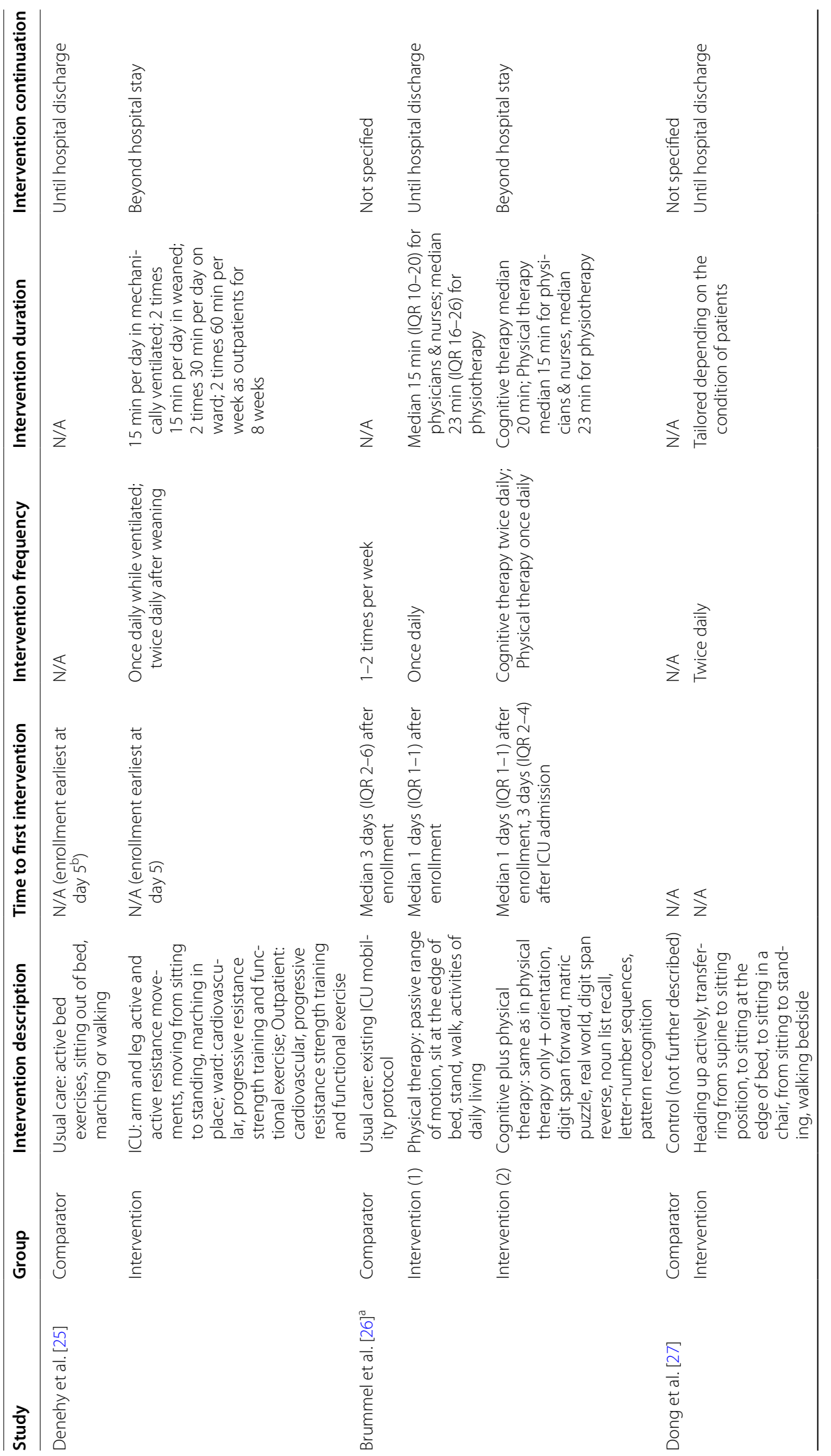




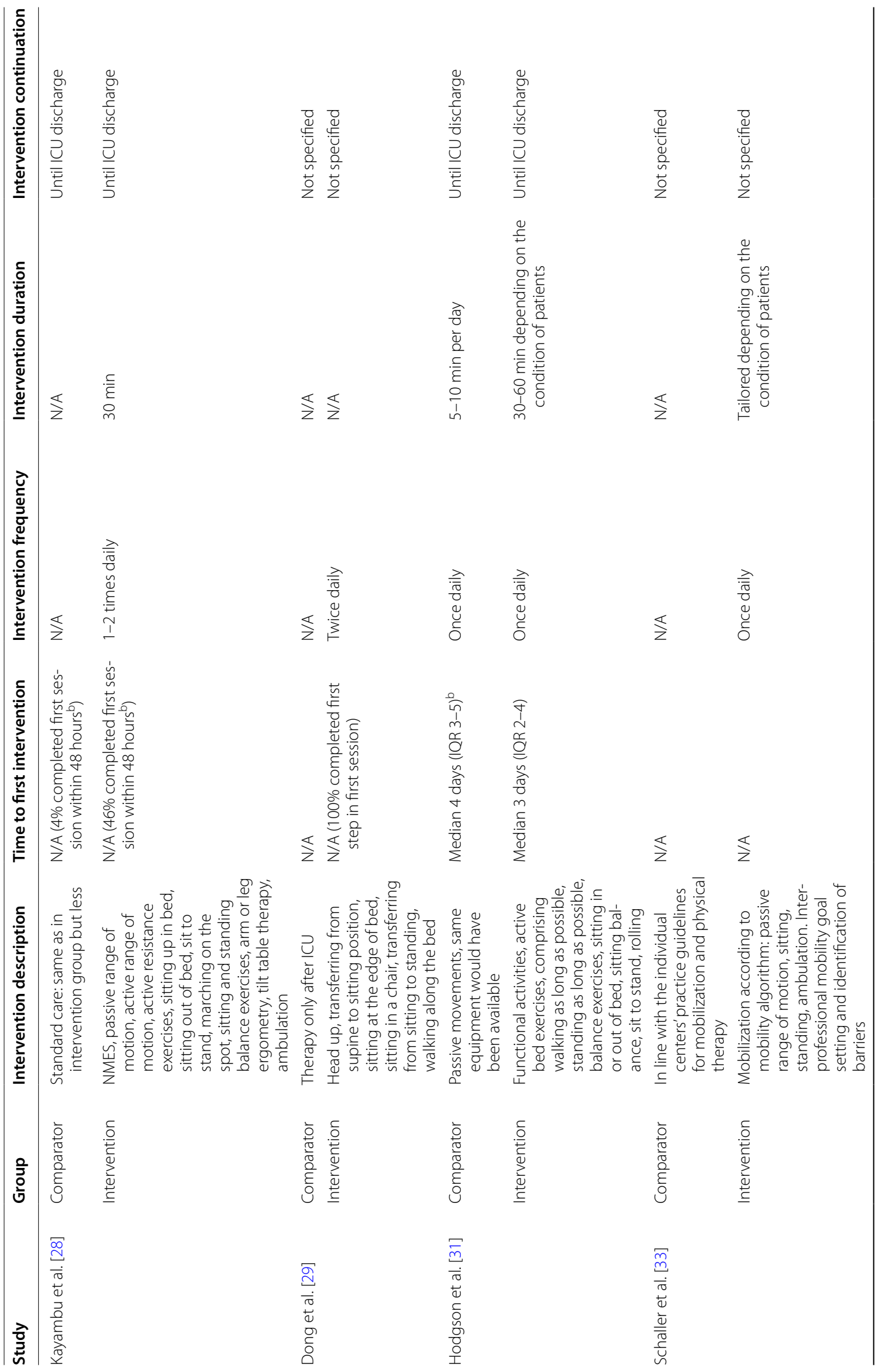




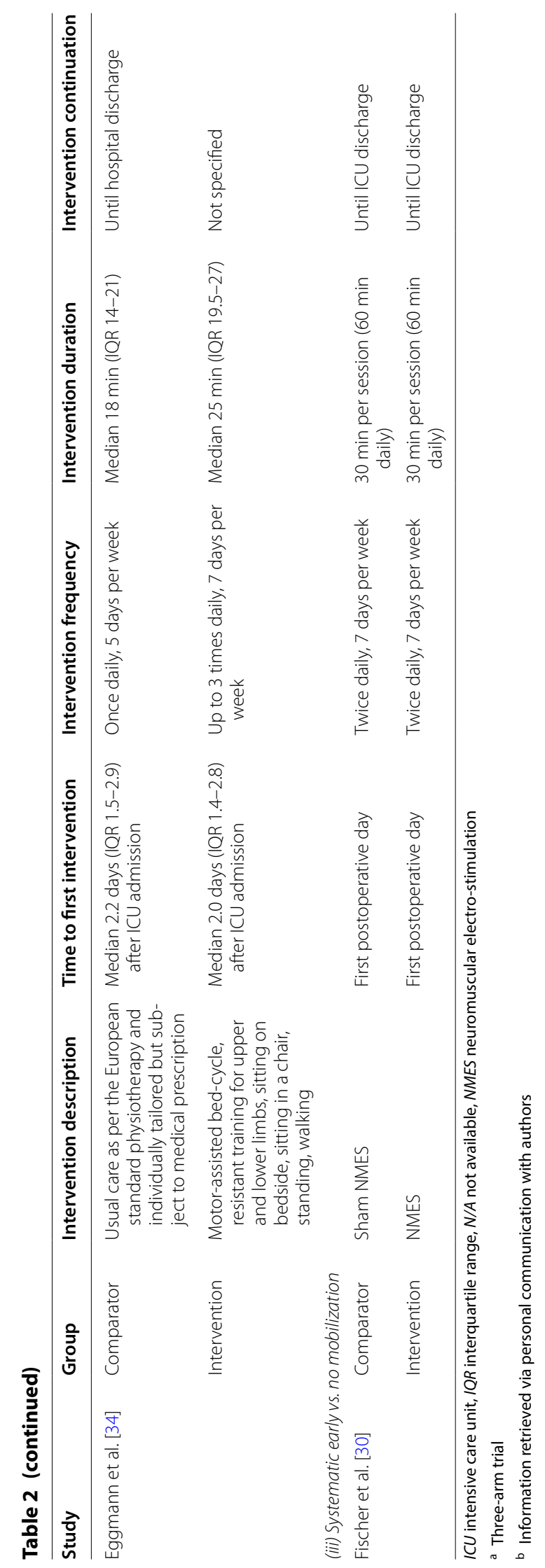




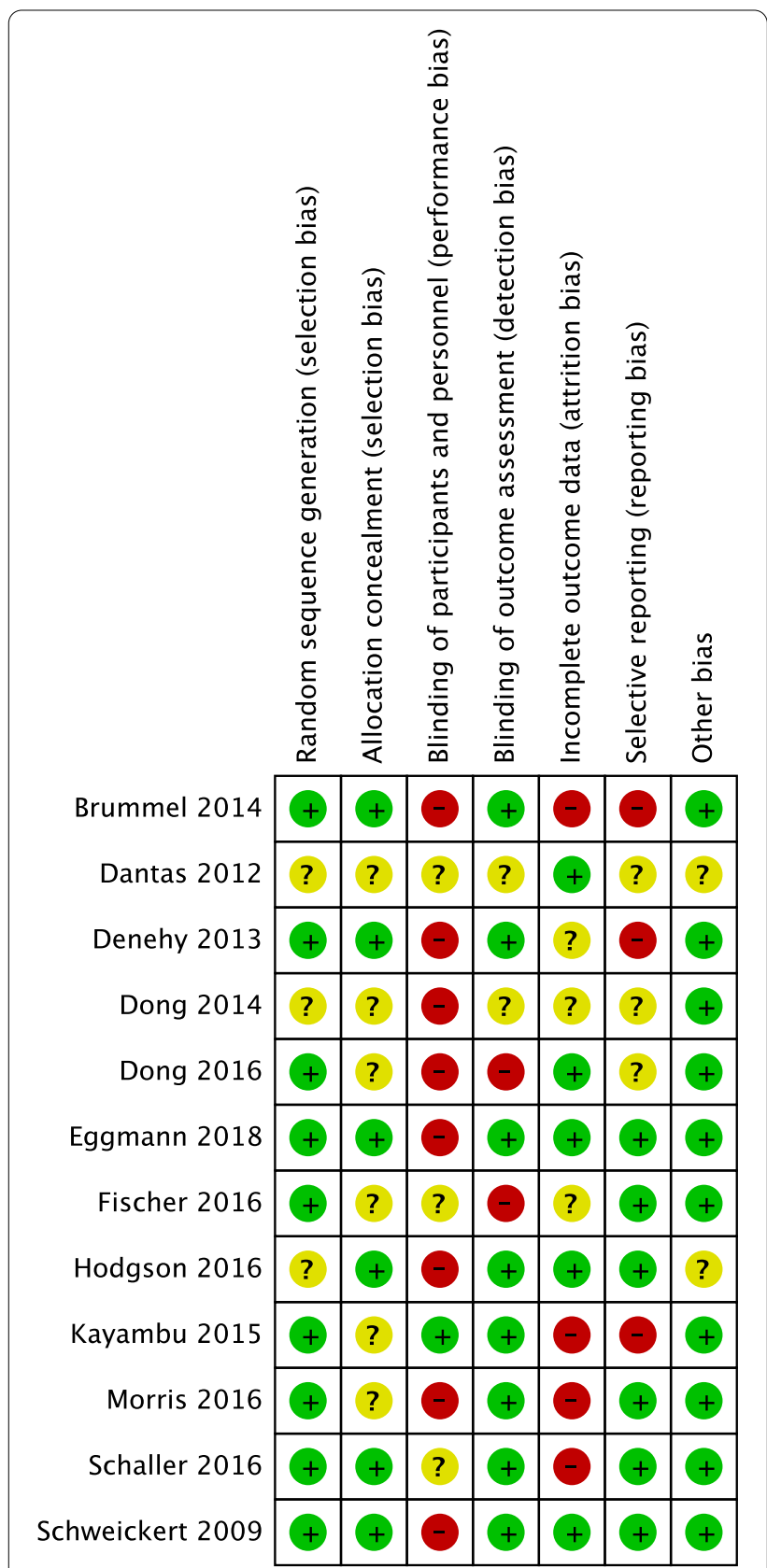

Fig. 2 Risk of bias assessment for the included studies all four studies (499 patients) showed no statistically significant difference in the incidence of ICUAW between groups (Fig. 3). However, the effects may be clinically meaningful, with a $38 \%$ reduction in the risk for developing ICUAW for systematic early mobilization compared with late mobilization (RR 0.62; 95\% CI 0.38-1.02; $p=0.06 ; I^{2}=0.0 \%$; one study; low certainty), and a $10 \%$ risk reduction for systematic early compared with standard early mobilization (RR 0.90; 95\% CI 0.63-1.27; $p=0.54 ; I^{2}=33.3 \%$; very low certainty).

\section{6-Min walk test}

Only two studies reported results on 6MWT [25, 34], both comparing systematic early with standard early mobilization. 6MWT distances achieved by study participants were comparable between the two studies. Denehy et al. demonstrated an increase in 6MWT distance in both groups from ICU discharge up to 12 months of follow-up [25]. While there was no difference in 6MWT distances between groups beyond ICU discharge, they reported a statistically significantly higher mean change from baseline at 3 months (MD $63.7 \mathrm{~m}$; 95\% CI 14.2113.2; $p<0.05$ ) and 12 months (MD $72.7 \mathrm{~m} ; 95 \% \mathrm{CI}$ 9.3-135.8; $p<0.05)$ in the systematic early mobilization group. Eggmann et al. did not find evidence for a difference in 6MWT distance between groups at hospital discharge [34]. We judged the certainty of evidence for a benefit of systematic early mobilization on $6 \mathrm{MWT}$ compared to standard early mobilization as low.

\section{Time needed until walking}

Three studies reported on the time needed by patients until walking for the first time [23, 31, 34]. Schweickert et al. reported a statistically significantly shorter time to walking in the systematic early mobilization group when compared to late mobilization (low certainty) [23]. In contrast, Hodgson et al. did not find a between-group difference when comparing systematic early with standard early mobilization (very low certainty) [31]. Data from Eggmann et al. were insufficient to draw a conclusion [34].

\section{Proportion of patients returning to independence from assistance}

Only the study by Schweickert et al. reported the proportion of patients returning to independence from assistance during hospitalization [23]. They found a statistically significantly higher proportion of patients reaching independence in the systematic early mobilization group compared to the late mobilization group (low certainty).

\section{SF-36 Physical Function Domain Score}

Four studies reported results on SF-36 PFS achieved by study participants at 6 months after hospital discharge $[25,28,32,34]$. There were considerable differences between studies, as Kayambu et al. and Eggmann et al. measured higher scores than Denehy et al. and Morris et al. While Morris et al. found a statistically significant difference between the systematic early mobilization group and the late mobilization group [32], none of the 


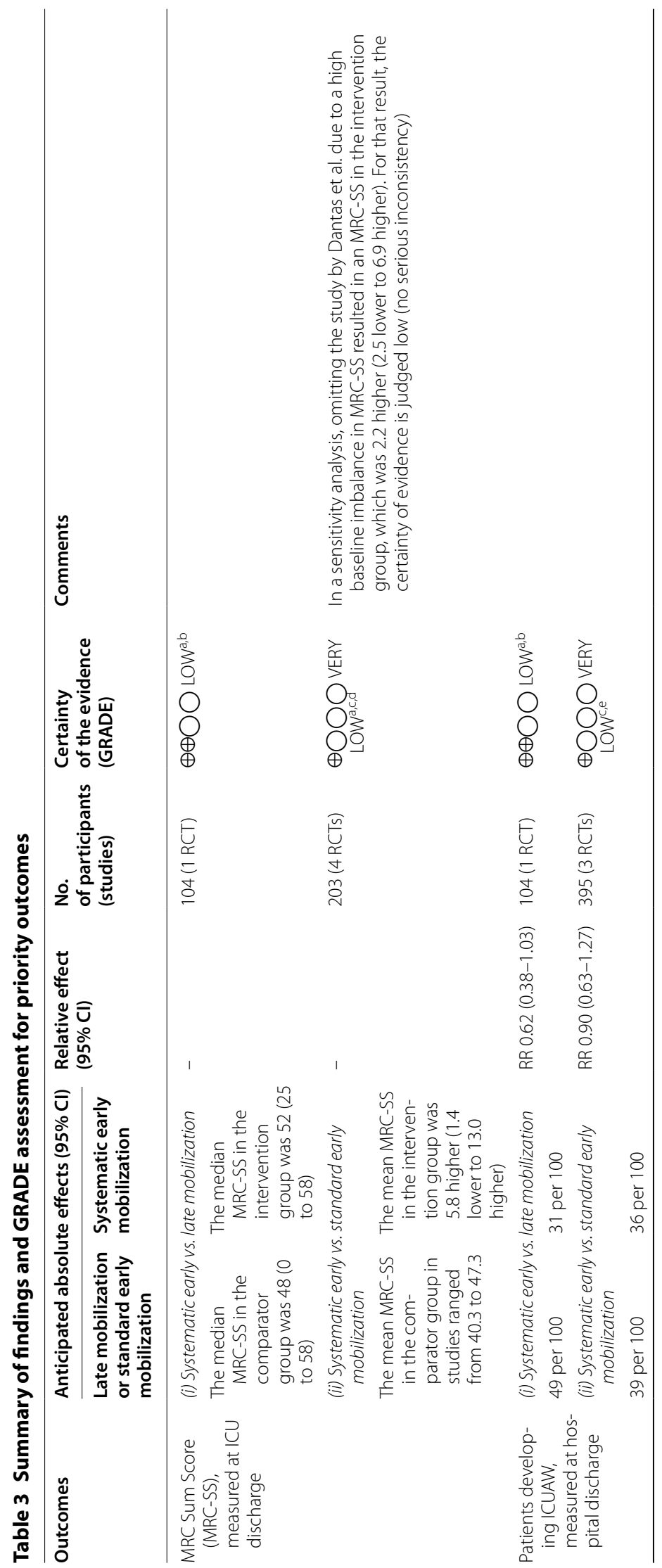




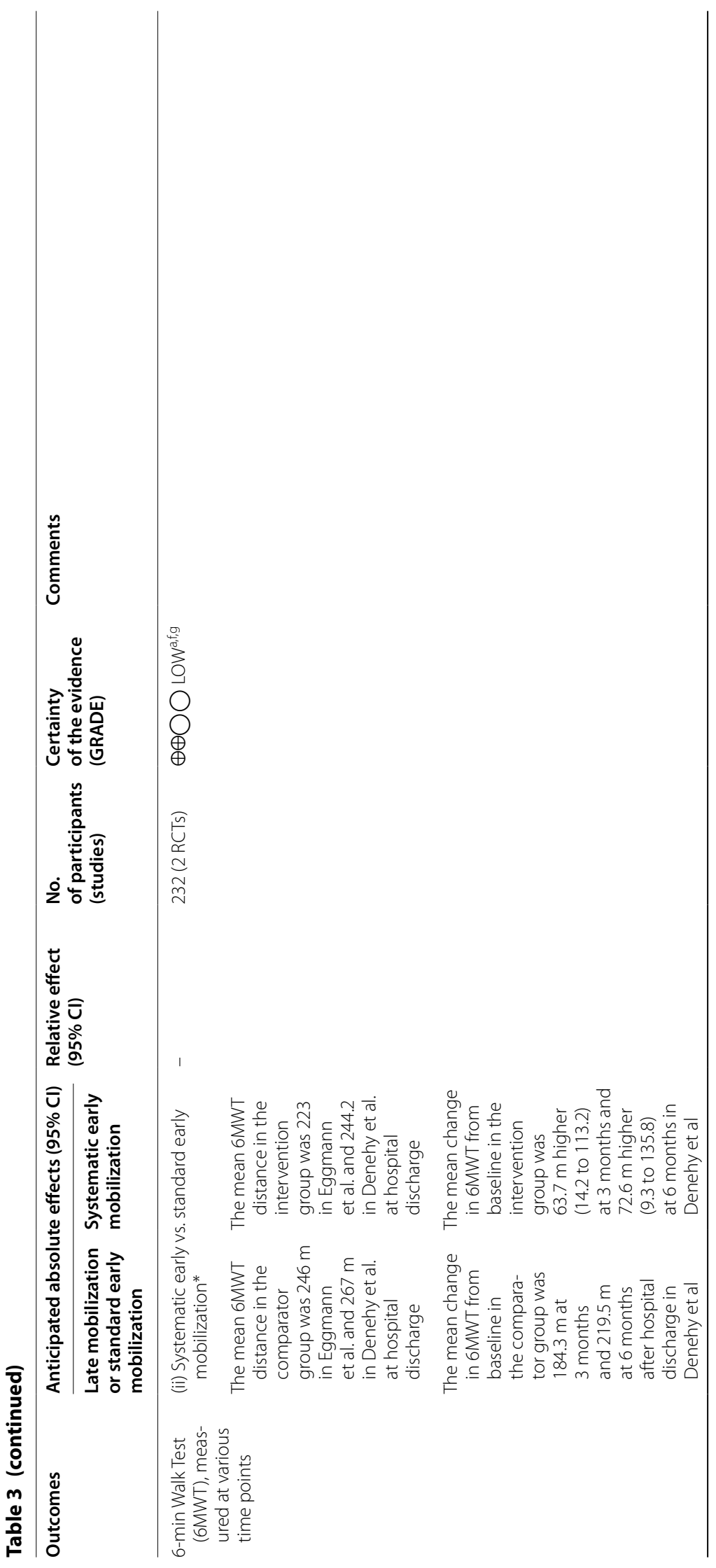




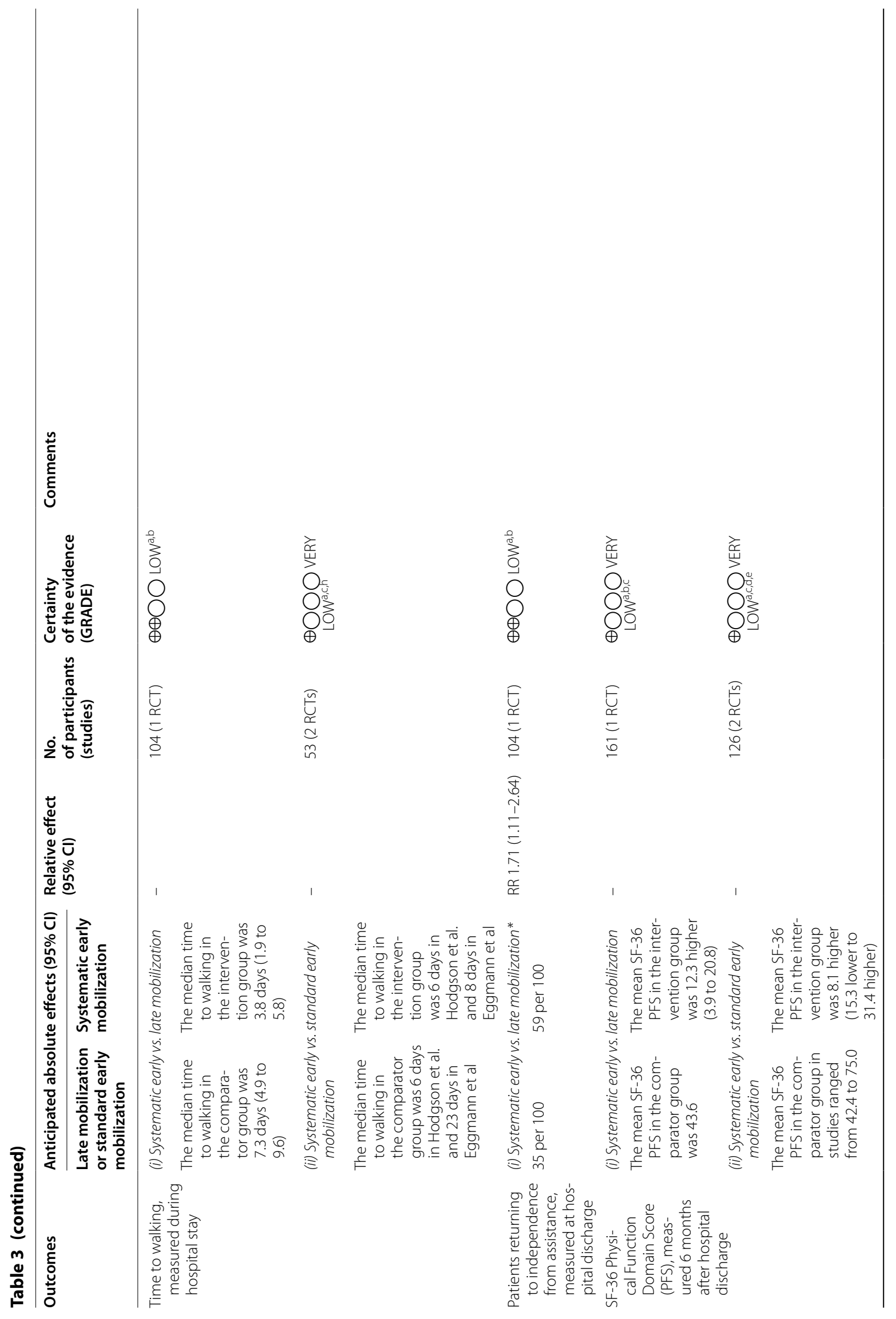




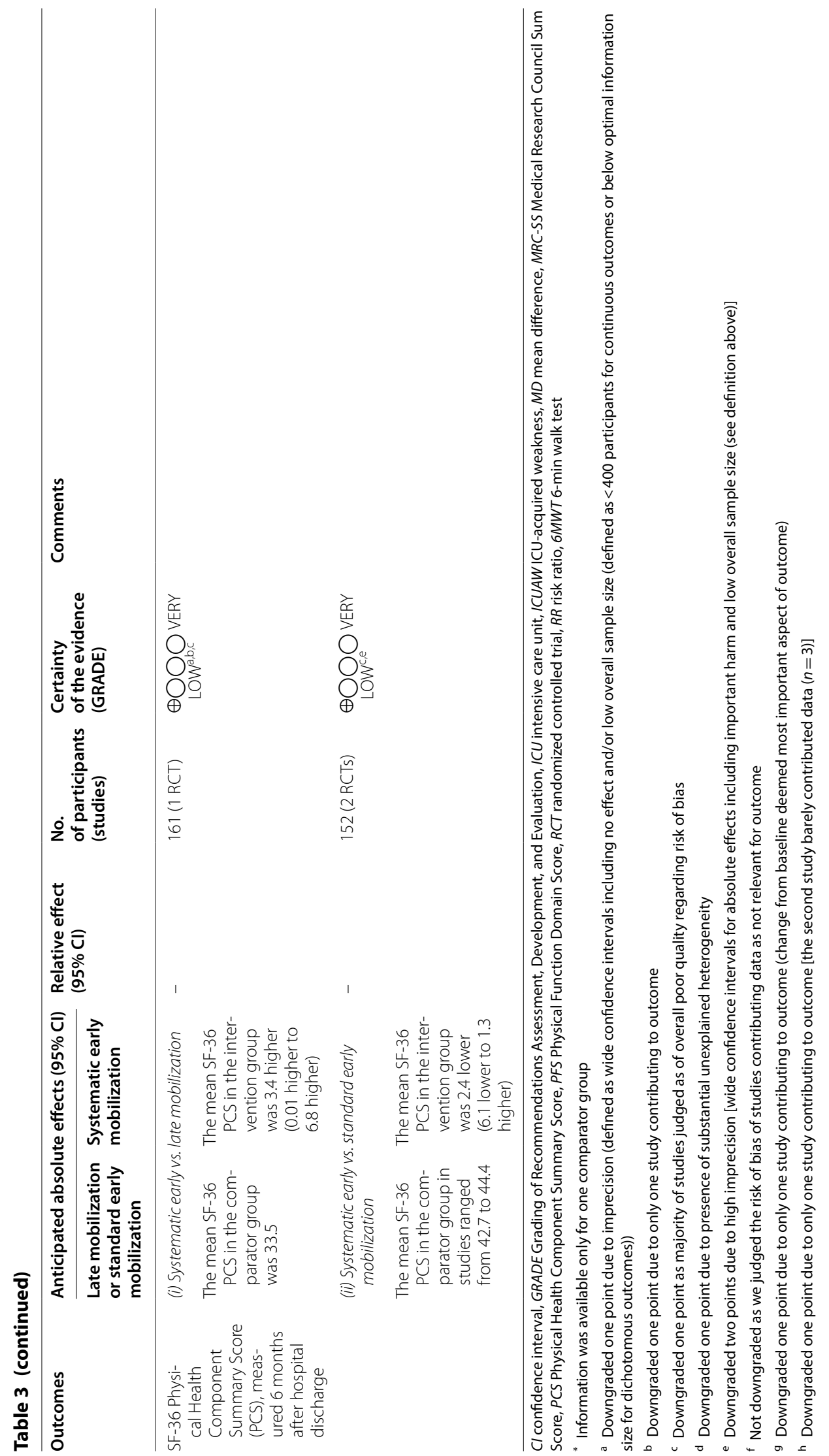




\section{MRC Sum Score}

Author \& Year

Mean Difference

Systematic early vs. standard early mobilization

Dantas et al., 2012

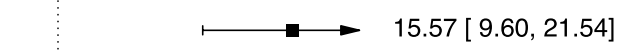

Kayambu et al., 2015

Hodgson et al., 2016

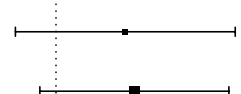

$4.60[-2.69,11.89]$

Eggmann et al., 2018

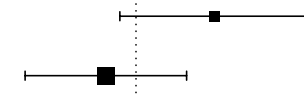

$5.20[-1.07,11.47]$

$-2.00[-7.36,3.36]$

Fixed-Effects Model $(p=0.000)$

Random-Effects Model $(\mathrm{p}=0.115)$

Heterogeneity: $Q=18.53, d f=3, p=0.00 ; / \wedge 2=81.71 \%$

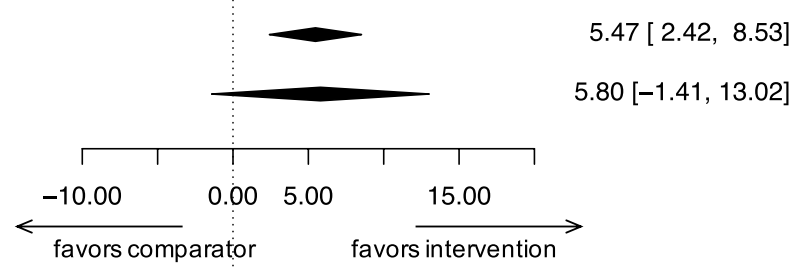

Incidence of ICU-Acquired Weakness

Author \& Year

Comparator Intervention

Risk Ratio

\section{Systematic early vs. late mobilization}

Schweickert et al., 2009

$27 / 55$

$15 / 49$

$0.62[0.38,1.03]$

Subgroup Model $(\mathrm{p}=0.064)$

Heterogeneity: $Q=0.00, d f=0, p=1.00 ; 112=0.00 \%$

Systematic early vs. standard early mobilization

Denehy et al., 2013

$13 / 76$

$16 / 74$

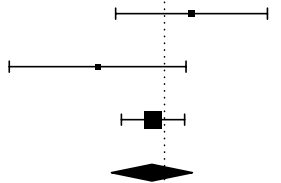

$1.26[0.65,2.44]$

Hodgson et al., 2016

$10 / 20$

$7 / 25$

Schaller et al., 2016

$51 / 96$

$50 / 104$

Subgroup Model $(p=0.542)$

Heterogeneity: $Q=2.50, d f=2, p=0.29 ; 1 \wedge 2=29.71 \%$

Fixed-Effects Model $(p=0.120)$

Random-Effects Model ( $\mathrm{p}=0.203$ )

Heterogeneity: $Q=4.20, d f=3, p=0.24 ; 1^{\wedge} 2=33.87 \%$

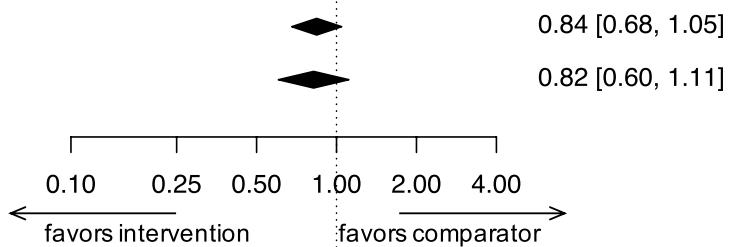

Fig. 3 Meta-analysis results on MRC Sum Scores at ICU discharge and proportion of patients developing ICU-acquired weakness during hospitalization

other studies found such a difference compared with standard early mobilization $[25,28,34]$. The results from three studies (287 patients) $[25,28,32]$ were included in a meta-analysis (Fig. 4), which showed a statistically significant improvement of SF-36 PFS at 6 months after hospital discharge in the systematic early mobilization group 
compared to the late mobilization group (MD 12.3; 95\% CI 3.9-20.8; $p=0.004$; one study; very low certainty). However, we found no evidence for such an effect for the comparison of systematic early with standard early mobilization (MD 8.1; 95\% CI -15.3 to 31.4; $p=0.50$; very low certainty). Heterogeneity for the latter comparison was considerable $\left(I^{2}=83.1 \%\right)$ due to large between-study differences in measured SF-36 PFS [25, 28].

\section{SF-36 Physical Health Component Summary Score}

Out of the three studies reporting results on achieved SF-36 PCS at 6 months after hospital discharge [25, 32, 34], only Morris et al. showed a statistically significant difference between groups [32]. When pooling data from all three studies in a meta-analysis (313 patients), there was some evidence that participants receiving systematic early mobilization achieved higher SF-36 PCS compared to those receiving late mobilization (MD 3.4; $95 \%$ CI $0.01-6.8 ; p=0.050$; one study; low certainty). However, there was no evidence for a difference when comparing systematic early with standard early mobilization (MD $-2.4 ; 95 \% \mathrm{CI}-6.1$ to $1.3 ; p=0.20 ; I^{2}=0.0 \%$; low certainty).

\section{Additional outcomes}

In summary, the evidence regarding the benefits of systematic early mobilization was inconclusive across various other outcomes related to muscle strength and physical function (see Additional file 3 for details). While rather weak in general, the evidence was commonly stronger for the comparison between systematic early and late mobilization than for the comparison between systematic early and standard early mobilization. We found no conclusive evidence for an effect on quality of life, cognitive and mental health outcomes, length of ICU or hospital stay, duration of mechanical ventilation or in-hospital or postdischarge mortality. Adverse effects were reported infrequently, with no apparent difference between studies investigating systematic early compared to late mobilization and studies investigating systematic early compared to standard early mobilization.

\section{Discussion}

\section{Summary of main results}

In this systematic review and meta-analysis, we only found little evidence for a beneficial effect of systematic early mobilization on MRC-SS, incidence of ICUAW, $6 \mathrm{MWT}$ performance, time needed until walking, proportion of patients returning to independence from assistance, SF-36 PFS and SF-36 PCS. While there was a general trend for an improvement in patient outcomes across trials, we found no evidence in support of systematic early mobilization when compared with standard early mobilization. Effects were generally stronger for the comparison of systematic early with late mobilization, and there was low to very low certainty evidence for a benefit with respect to the time to walking, return to independence, as well as SF-36 PFS and PCS at 6 months after discharge (see Additional file 4). Results were similar between groups for further outcomes related to muscle strength and physical function outcomes, cognitive and mental health outcomes, health-related quality of life, length of stay, duration of ventilation and mortality. Systematic early mobilization appeared safe when conducted under adequate monitoring.

\section{Interpretation}

We found considerable heterogeneity between the included studies. First, there were important differences in study populations. While most studies included a mixed ICU collective, three were limited to postoperative [27, 30] or septic patients [28]. There were large differences between studies in the average length of ICU and hospital stay, as well as in the duration of mechanical ventilation, indicating marked differences in patient recovery between studies. However, on a study level, longer hospitalization and ventilation were barely associated with higher disease severity, as reflected by average Acute Physiologic Assessment and Chronic Health Evaluation (APACHE) scores. We thus consider it likely that these differences were due to variations in standard ICU practices, reasons for ICU admission or other patient characteristics.

Second, there were differences in the interventions provided in the studies. While almost all studies described a diverse set of exercises, tailored to the patient's capability and increasing intensity over time, the systematic early mobilization interventions differed markedly in their scope, intensity and composition between studies. Furthermore, the allocated intervention extended beyond hospital discharge in two studies $[25,26]$, which did not appear to result in stronger effects on muscle strength or physical function.

Third, the definition of 'early mobilization' and its distinction from 'standard care' were often unclear and varied strongly between studies. Standard care was often poorly described, and not all studies reported on differences in the timing of the first mobilization between study arms. Our approach of categorizing studies in comparing systematic early mobilization with either late mobilization or standard early mobilization partially accounted for this issue and revealed that the 


\section{SF-36 Physical Function Domain Score (PFS)}

Author \& Year

Mean Difference

Systematic early vs. late mobilization

Morris et al., 2016

Subgroup Model $(\mathrm{p}=0.004)$

Heterogeneity: $Q=0.00, d f=0, p=1.00 ; 1 \wedge 2=0.00 \%$

Systematic early vs. standard early mobilization

Denehy et al., 2013

Kayambu et al., 2015

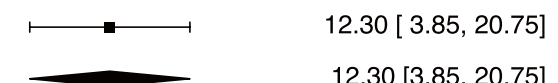

Subgroup Model $(\mathrm{p}=0.500)$

Heterogeneity: $Q=5.88, d f=1, p=0.02 ; 1 \wedge 2=83.01 \%$

Fixed-Effects Model $(p=0.142)$

Random-Effects Model ( $p=0.202)$

Heterogeneity: $Q=11.87, d f=2, p=0.00 ; 1 \wedge 2=83.07 \%$

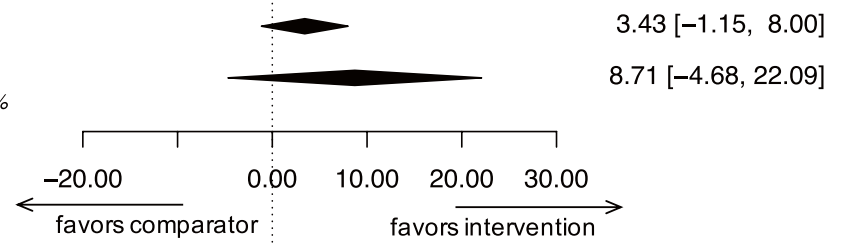

SF-36 Physical Health Component Score (PCS)

Author \& Year

Mean Difference

Systematic early vs. late mobilization

Morris et al., 2016

Subgroup Model $(p=0.050)$

Heterogeneity: $Q=0.00, d f=0, p=1.00 ; 1 \wedge 2=0.00 \%$

Systematic early vs. standard early mobilization

Denehy et al., 2013

$-2.80[-7.66,2.06]$

Eggmann et al., 2018

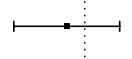

$-1.90[-7.49,3.69]$

Subgroup Model $(\mathrm{p}=0.197)$

Heterogeneity: $Q=0.06, d f=1, p=0.81 ; 1 \wedge 2=0.00 \%$

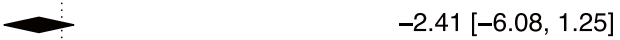

Fixed-Effects Model $(\mathrm{p}=0.573)$

Random-Effects Model $(\mathrm{p}=0.997)$

Heterogeneity: $Q=5.26, d f=2, p=0.07 ; / 12=56.41 \%$

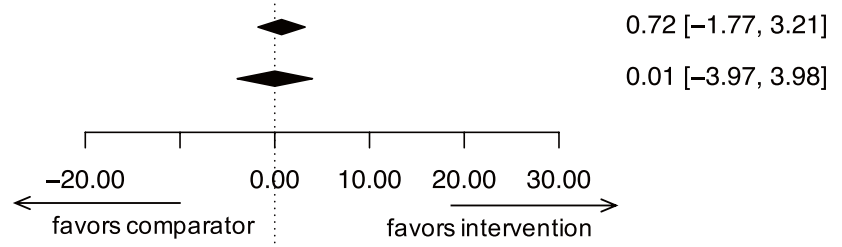

Fig. 4 Meta-analysis results on SF-36 Physical Function Domain Scores (PFS) and Physical Health Component Summary Scores (PCS) at 6 months after hospital discharge

timing of mobilization in the comparator group may be an important explanatory factor for differences in effects between trials. It is possible that standard practice has evolved after earlier studies on early mobilization found strong effects compared with late mobilization, such as the one by Schweickert et al. [23]. 
This may have resulted in smaller differences in effects between intervention and control groups, especially in more recent trials which we categorized as comparing systematic early with standard early mobilization.

Finally, we judged most studies to be at risk of bias, which also affected our confidence in most estimates in the GRADE assessment. However, considering results from studies at low risk of bias only would have led to the same conclusions.

\section{Results in context}

Several systematic reviews have addressed early mobilization in recent years $[12-15,35,36]$. Conclusions drawn by these reviews differ as to whether or not the evidence is sufficiently strong to conclude that early mobilization provides a benefit on muscle strength, physical function, quality of life, mortality, length of stay and other outcomes. While Doiron et al. and Castro-Avila et al. reported no statistically significant effects on outcomes related to muscle strength and physical function [14, 15], Fuke et al., Okada et al. and Zang et al. found a statistically significant benefit with early mobilization $[12,13$, 35]. This discrepancy primarily stems from slight differences in the inclusion of RCTs. Our review excluded some studies that were included in other reviews due to ineligibility of the study population [37-39] or late initiation of the mobilization intervention [40]. Conversely, we included the recent study by Eggmann et al. [34], which found no evidence for a benefit comparing early mobilization with standard care with a very small timing difference between groups (median 47 vs. $52 \mathrm{~h}$ ). This may explain why our review did not find sufficient evidence to conclude an effect of early mobilization on muscle strength or physical function outcomes.

As discussed by other authors, the definition of 'early mobilization' varies strongly across studies. [4, 41]. While there is no uniform consensus, the field appears to increasingly define early mobilization as starting within $72 \mathrm{~h}$ of ICU admission [4, 6]. Ding et al. attempted to identify the optimal starting time for early mobilization in a network meta-analysis of $15 \mathrm{RCTs}$, from which they concluded that initiation of mobilization within 72-96 h of mechanical ventilation would be most beneficial for the improvement of ICUAW [36]. Unfortunately, their analysis did not account for timing differences between intervention and comparator groups.

However, the difference in timing between intervention and comparator group may be an important determinant for identifying a benefit of systematic early mobilization in studies. Our findings suggest that systematic early mobilization may be effective when compared to late mobilization, but there was insufficient evidence for a benefit of systematic early mobilization compared to standard early mobilization. Thus, the difference in timing between intervention and comparator groups may be at least as important as the absolute timing of the first mobilization in the intervention group. We consider the separate analysis of different comparator categories a unique strength of our systematic review, as this contrast sheds light on an important issue when interpreting the available evidence on early mobilization. Treatment recommendations on early mobilization need to consider comparator group interventions in trials to judge whether more systematic or earlier mobilization approaches may provide additional clinical benefits over standard care and are cost-effective in the respective context.

\section{Limitations}

Several limitations should be considered when interpreting our findings. First, we defined 'early mobilization' as mobilization starting within 7 days of ICU admission in line with previous reviews on the subject [12, 14]. Using a stricter definition limiting the intervention to early mobilization within $72 \mathrm{~h}$ after ICU admission would have led to the exclusion of one study [25] and re-categorization of two studies into the late mobilization category [26, $31]$. This would have resulted in an even weaker evidence base for systematic early mobilization compared to both late mobilization and standard early mobilization. However, it would not have altered our main conclusions.

Second, we categorized studies into comparator categories based on predefined criteria. Due to the heterogeneity of 'early mobilization' between studies, it could occur that the comparator in one study was similar in timing or nature to the experimental intervention in another study, or vice versa. This was especially the case in the standard early mobilization category. Alternative assessments showed that if studies for which the timing difference between intervention and comparator group was unclear were excluded from analysis, this would not have altered our conclusions for any of the priority outcomes. Had these studies been assigned to the late mobilization category, we would have found smaller and not statistically significant effects on MRCSS, incidence of ICUAW, SF-36 PFS and PCS for the comparison between systematic early and late mobilization. However, our conclusions regarding the comparison between systematic early and standard early mobilization would have remained unchanged. Since our categorization may not fully reflect the timing differences between studies, a more detailed consideration of interventions and comparators in the individual studies may be warranted when making recommendations for practice.

Third, we excluded studies with relevant proportions of neurological, burns, transplant or postoperative patients 
requiring only short ventilation. This, as well as the language restriction, may have led to the exclusion of some studies that would have provided additional evidence and could have altered our results.

Fourth, we did not conduct a more detailed analysis of the frequency, duration and intensity, or exact implementation of the interventions. While these factors are likely to influence the effectiveness of interventions, the available information did not provide a sufficient basis for such comparisons.

Finally, we did not perform subgroup analyses other than by comparator category. While it is possible that specific patient subgroups may benefit more strongly from early mobilization than others, the available data were insufficient to conduct such subgroup analyses.

\section{Conclusion}

This systematic review and meta-analysis found a beneficial effect of systematic early mobilization in mechanically ventilated adult ICU patients on muscle strength and physical function when compared to late mobilization, but did not find evidence for such an effect when compared to standard early mobilization initiated within 7 days of ICU admission. This contrast widens the perspective on early mobilization in the ICU, highlighting the need to consider the characteristics of comparator interventions when interpreting RCT-based evidence to make recommendations for clinical practice.

\section{Supplementary Information}

The online version contains supplementary material available at https://doi. org/10.1186/s13054-020-03446-9.

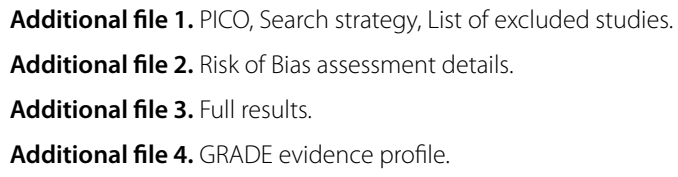

\begin{abstract}
Abbreviations
AMSTAR: Assessing the Methodology of Systematic Reviews; APACHE: Acute Physiologic Assessment and Chronic Health Evaluation; Cl: Confidence interval; GRADE: Grading of Recommendations Assessment, Development and Evaluation; ICU: Intensive care unit; ICUAW: Intensive care unit-acquired weakness; IQR: Interquartile range; MD: Mean difference; MRC-SS: Medical Research Council Sum Score; PRISMA: Preferred Reporting Items for Systematic Reviews and Meta-Analyses; RCT: Randomized controlled trial; RR: Risk ratio; SF-36 PFS: Short Form 36 Physical Function Domain Score; SF-36 PCS: Short Form 36
\end{abstract} Physical Health Component Summary Score; 6MWT: 6-Min Walk Test.

\section{Acknowledgements}

The authors would like to thank the following ICU specialists for supporting the project with their expertise: Prof. Dr. med. Thierry Fumeaux (President SGI-SSMI-SSMI/Hôpital de Nyon, Switzerland), Prof. Dr. med. Bara Ricou (Hôpitaux Universitaires Genève, Switzerland), Dr. med. Martin Tramèr (Hôpitaux
Universitaires Genève, Switzerland), Prof. Dr. Med. Philippe Eckert (Centre Hospitalier Universitaire Vaudois, Switzerland), Dr. med. Antje Heise (Spital Thun, Switzerland), Prof. Dr. Med. Marco Maggiorini (UniversitätsSpital Zürich, Switzerland), Prof. Dr. Marie-Madlen Jeitziner (Inselspital Bern, Switzerland), Conrad Wesch (Universitätsspital Basel, Switzerland), Pia Fankhauser (Physioswiss), Heidi Boksberger (UniversitätsSpital Zürich, Switzerland) and Dr. med. Stefan Bützberger (AarReha Schinznach, Switzerland). Furthermore, the authors would like to thank the following ICU specialists for sharing further information about their studies: Prof. Dr. Eduardo França (Physiotherapy Department, Federal University of Paraíba, Brazil), Dr. Lara Edbrooke (School of Physiotherapy, University of Melbourne, Australia), Prof. Dr. Linda Denehy (Melbourne School of Health Sciences, University of Melbourne, Australia), Dr. Geetha Kayambu (Department of Rehabilitation, National University Hospital, Singapore), Prof. Dr. Carol Hodgson (Department of Epidemiology and Preventive Medicine, Monash University, Australia) and Mr. Heru Suwardianto (Emergency and Critical Care Department, HIPERCCI East Java, HIPMEBI Center, Indonesia).

\section{Authors' contributions}

$D M, Y T, M S, M P$ and HY contributed to the conception and design of this review. DM, BS and HY performed the two-stage literature screening, extracted the data and conducted the risk of bias assessment. DM and HY statistically analyzed the data. DM, BS and HY interpreted and synthesized the data. MP functioned as a senior reviewer, supervised the analysis and advised the interpretation of results. DM and BS wrote the draft manuscript. YT, MS, MP and HY critically revised the manuscript. All authors read and approved the final manuscript.

\section{Funding}

This research project was funded by the Swiss Medical Board and the Swiss Federal Office of Public Health. The funding bodies determined the topic of the study together with the authors and external ICU specialists. The funding bodies had no influence on the conduct, analysis and interpretation of the study and were not involved in writing the manuscript.

\section{Availability of data and materials}

All data generated and/or analyzed during the current study are included within the published article and its additional files.

\section{Ethics approval and consent to participate}

As a systematic review and meta-analysis based on aggregate-level data from published RCTs, this study does not require ethics approval under the Swiss Human Research Act.

\section{Consent for publication}

Not applicable.

\section{Competing interests}

The authors declare that they have no competing interests.

\section{Author details}

${ }^{1}$ Department of Epidemiology, Epidemiology, Biostatistics and Prevention Institute (EBPI), University of Zurich, Hirschengraben 84, 8001 Zurich, Switzerland. ${ }^{2}$ Faculty of Medicine (MeF), University of Zurich, Pestalozzistrasse 3, 8091 Zurich, Switzerland. ${ }^{3}$ Institute of Pharmaceutical Medicine (ECPM), University of Basel, Klingelbergstrasse 61, 4056 Basel, Switzerland.

Received: 13 July 2020 Accepted: 18 December 2020

Published online: 06 January 2021

\section{References}

1. Inoue S, Hatakeyama J, Kondo Y, et al. Post-intensive care syndrome: its pathophysiology, prevention, and future directions. Acute Med Surg. 2019;6:233-46. https://doi.org/10.1002/ams2.415.

2. Iwashyna TJ, Ely EW, Smith DM, et al. Long-term cognitive impairment and functional disability among survivors of severe sepsis. JAMA. 2010;304:1787-94. https://doi.org/10.1001/jama.2010.1553. 
3. Desai SV, Law TJ, Needham DM. Long-term complications of critical care. Crit Care Med. 2011;39:371-9. https://doi.org/10.1097/CCM.0b013e3181 fd66e5.

4. Fuest K, Schaller SJ. Recent evidence on early mobilization in criticalIIl patients. Curr Opin Anaesthesiol. 2018;31:144-50. https://doi. org/10.1097/ACO.0000000000000568.

5. Hodgson CL, Stiller K, Needham DM, et al. Expert consensus and recommendations on safety criteria for active mobilization of mechanically ventilated critically ill adults. Crit Care. 2014;18:658. https://doi.org/10.1186/ s13054-014-0658-y

6. Bein T, Bischoff M, Bruckner U, et al. S2e guideline: positioning and early mobilisation in prophylaxis or therapy of pulmonary disorders: revision 2015: S2e guideline of the German Society of Anaesthesiology and Intensive Care Medicine (DGAl). Anaesthesist. 2015;64(Suppl 1):1-26. https:// doi.org/10.1007/s00101-015-0071-1.

7. Agency for Healthcare Research and Quality (AHRQ). Early Mobility Guide for Reducing Ventilator-Associated Events in Mechanically Ventilated Patients. AHRQ Pub/ No. 1617-0018-4-EF 2017;:28.

8. Devlin JW, Skrobik Y, Gelinas C, et al. Clinical practice guidelines for the prevention and management of pain, agitation/sedation, delirium, immobility, and sleep disruption in adult patients in the ICU. Crit Care Med. 2018;46:e825-73. https://doi.org/10.1097/CCM.0000000000003299.

9. National Institute for Health and Care Excellence (NICE). Rehabilitation after critical illness in adults-Guidance. 2018. https://www.nice.org.uk/ guidance/cg83. Accessed 13 Apr 2020.

10. Kayambu G, Boots R, Paratz J. Physical therapy for the critically ill in the ICU: a systematic review and meta-analysis. Crit Care Med. 2013:41:154354. https://doi.org/10.1097/CCM.0b013e31827ca637.

11. Tipping CJ, Harrold M, Holland A, et al. The effects of active mobilisation and rehabilitation in ICU on mortality and function: a systematic review. Intensive Care Med. 2017;43:171-83. https://doi.org/10.1007/s0013 4-016-4612-0

12. Fuke R, Hifumi $T$, Kondo $Y$, et al. Early rehabilitation to prevent postintensive care syndrome in patients with critical illness: a systematic review and meta-analysis. BMJ Open. 2018;8:e019998. https://doi.org/10.1136/ bmjopen-2017-019998.

13. Okada Y, Unoki T, Matsuishi Y, et al. Early versus delayed mobilization for in-hospital mortality and health-related quality of life among critically ill patients: a systematic review and meta-analysis. J Intensive Care. 2019;7:57. https://doi.org/10.1186/s40560-019-0413-1.

14. Castro-Avila AC, Serón P, Fan E, et al. Effect of early rehabilitation during intensive care unit stay on functional status: systematic review and metaanalysis. PLoS ONE. 2015;10:e0130722. https://doi.org/10.1371/journ al.pone.0130722.

15. Doiron K, Hoffmann T, Beller E. Early intervention (mobilization or active exercise) for critically ill adults in the intensive care unit. Cochrane Datab Syst Rev. 2018. https://doi.org/10.1002/14651858.CD010754.pub2.

16. Liberati A, Altman DG, Tetzlaff J, et al. The PRISMA statement for reporting systematic reviews and meta-analyses of studies that evaluate healthcare interventions: explanation and elaboration. BMJ. 2009;339:b2700-b2700. https://doi.org/10.1136/bmj.b2700.

17. Cochrane Collaboration. Cochrane Handbook for Systematic Reviews of Interventions (version 5.1). 2011. http://handbook-5-1.cochrane.org/. Accessed 27 July 2018.

18. Shea BJ, Reeves BC, Wells G, et al. AMSTAR 2: a critical appraisal tool for systematic reviews that include randomised or non-randomised studies of healthcare interventions, or both. BMJ. 2017;358:j4008. https://doi. org/10.1136/bmj.j4008.

19. Cochrane Collaboration. The Cochrane highly sensitive search strategies for identifying randomized trials in PubMed. 2008. https://handbook-5-1. cochrane.org/chapter_6/box_6_4_a_cochrane_hsss_2008_sensm ax_pubmed.htm. Accessed 22 Feb 2019.

20. Higgins JPT, Altman DG, Gøtzsche PC, et al. The Cochrane Collaboration's tool for assessing risk of bias in randomised trials. BMJ. 2011;343:d5928. https://doi.org/10.1136/bmj.d5928.

21. Viswanathan M, Ansari MT, Berkman ND, et al. Assessing the Risk of Bias of Individual Studies in Systematic Reviews of Health Care Interventions. In: Methods Guide for Effectiveness and Comparative Effectiveness Reviews. Rockville (MD): Agency for Healthcare Research and Quality (US) 2008. http://www.ncbi.nlm.nih.gov/books/NBK91433/. Accessed 16 Jan 2020.
22. Guyatt G, Oxman AD, Akl EA, et al. GRADE guidelines. J Clin Epidemiol. 2011;64:383-94. https://doi.org/10.1016/j.jclinepi.2010.04.026.

23. Schweickert WD, Pohlman MC, Pohlman AS, et al. Early physical and occupational therapy in mechanically ventilated, critically ill patients: a randomised controlled trial. Lancet. 2009:373:1874-82. https://doi. org/10.1016/50140-6736(09)60658-9.

24. Dantas CM, dos Silva PFS, de Siqueira FHT, et al. Influence of early mobilization on respiratory and peripheral muscle strength in critically ill patients. Rev Bras Ter Intensiva. 2012;24:173-8. https://doi.org/10.1590/ S0103-507X2012000200013.

25. Denehy L, Skinner EH, Edbrooke L, et al. Exercise rehabilitation for patients with critical illness: a randomized controlled trial with 12 months of follow-up. Crit Care. 2013;17:R156. https://doi.org/10.1186/cc12835.

26. Brummel NE, Girard TD, Ely EW, et al. Feasibility and safety of early combined cognitive and physical therapy for critically ill medical and surgical patients: the Activity and Cognitive Therapy in ICU (ACT-ICU) trial. Intensive Care Med. 2014;40:370-9. https://doi.org/10.1007/s0013 4-013-3136-0.

27. Dong Z, Yu B, Sun Y, et al. Effects of early rehabilitation therapy on patients with mechanical ventilation. World J Emerg Med. 2014;5:48-52. https://doi.org/10.5847/wjem.j.issn.1920-8642.2014.01.008.

28. Kayambu G, Boots R, Paratz J. Early physical rehabilitation in intensive care patients with sepsis syndromes: a pilot randomised controlled trial. Intensive Care Med. 2015;41:865-74. https://doi.org/10.1007/s0013 4-015-3763-8.

29. Dong Z, Yu B, Zhang Q, et al. Early rehabilitation therapy is beneficial for patients with prolonged mechanical ventilation after coronary artery bypass surgery. Int Heart J. 2016;57:241-6. https://doi.org/10.1536/ ihj.15-316.

30. Fischer A, Spiegl M, Altmann K, et al. Muscle mass, strength and functional outcomes in critically ill patients after cardiothoracic surgery: does neuromuscular electrical stimulation help? The Catastim 2 randomized controlled trial. Crit Care. 2016;20:30. https://doi.org/10.1186/s1305 4-016-1199-3.

31. Hodgson CL, Bailey M, Bellomo R, et al. A binational multicenter pilot feasibility randomized controlled trial of early goal-directed mobilization in the ICU. Crit Care Med. 2016;44:1145. https://doi.org/10.1097/CCM.00000 00000001643.

32. Morris PE, Berry MJ, Files DC, et al. Standardized rehabilitation and hospital length of stay among patients with acute respiratory failure: a randomized clinical trial. JAMA. 2016;315:2694-702. https://doi.org/10.1001/ jama.2016.7201.

33. Schaller SJ, Anstey M, Blobner M, et al. Early, goal-directed mobilisation in the surgical intensive care unit: a randomised controlled trial. Lancet. 2016;388:1377-88. https://doi.org/10.1016/S0140-6736(16)31637-3.

34. Eggmann $\mathrm{S}$, Verra $\mathrm{ML}$, Luder $\mathrm{G}$, et al. Effects of early, combined endurance and resistance training in mechanically ventilated, critically ill patients: a randomised controlled trial. PLOS ONE. 2018;13:e0207428. https://doi. org/10.1371/journal.pone.0207428.

35. Zang $K$, Chen $B$, Wang $M$, et al. The effect of early mobilization in critically ill patients: a meta-analysis. Nurs Crit Care. 2019. https://doi.org/10.1111/ nicc. 12455

36. Ding $N$, Zhang Z, Zhang $C$, et al. What is the optimum time for initiation of early mobilization in mechanically ventilated patients? A network meta-analysis. PLoS ONE. 2019;14:e0223151. https://doi.org/10.1371/ journal.pone.0223151.

37. Patman S, Sanderson D, Blackmore M. Physiotherapy following cardiac surgery: is it necessary during the intubation period? Aust J Physiother. 2001;47:7-16. https://doi.org/10.1016/50004-9514(14)60294-4.

38. Burtin C, Clerckx B, Robbeets C, et al. Early exercise in critically ill patients enhances short-term functional recovery*. Crit Care Med. 2009;37:2499505. https://doi.org/10.1097/CCM.0b013e3181a38937.

39. Maffei $P$, Wiramus $S$, Bensoussan $L$, et al. Intensive early rehabilitation in the intensive care unit for liver transplant recipients: a randomized controlled trial. Arch Phys Med Rehabil. 2017;98:1518-25. https://doi. org/10.1016/.apmr.2017.01.028.

40. Moss M, Nordon-Craft A, Malone D, et al. A randomized trial of an intensive physical therapy program for patients with acute respiratory failure. Am J Respir Crit Care Med. 2016;193:1101-10. https://doi.org/10.1164/ rccm.201505-10390C. 
41. Clarissa C, Salisbury L, Rodgers S, et al. Early mobilisation in mechanically ventilated patients: a systematic integrative review of definitions and activities. J Intensive Care. 2019;7:3. https://doi.org/10.1186/s4056 0-018-0355-z.

\section{Publisher's Note}

Springer Nature remains neutral with regard to jurisdictional claims in published maps and institutional affiliations.
Ready to submit your research? Choose BMC and benefit from:

- fast, convenient online submission

- thorough peer review by experienced researchers in your field

- rapid publication on acceptance

- support for research data, including large and complex data types

- gold Open Access which fosters wider collaboration and increased citations

- maximum visibility for your research: over $100 \mathrm{M}$ website views per year

At BMC, research is always in progress.

Learn more biomedcentral.com/submissions 